\title{
A psicopatologia e o diagnóstico numa abordagem fenomenológica-existencial
}

\author{
Carlene Maria Dias Tenório ${ }^{l}$
}

\begin{abstract}
RESUMO - Partindo da exposição de alguns pressupostos da fenomenologia e do existencialismo, é feita uma reflexão acerca dos aspectos teóricos e metodológicos referentes à psicopatologia e ao diagnóstico dentro dessa abordagem. Uma psicologia de base fenomenológico-existencial confirma a prioridade da relação com o outro na constituição do sujeito. Desse modo, o aspecto relacional assume um papel determinante no desenvolvimento saudável ou patológico e o aspecto essencial da existência humana, do qual se origina a problemática relacional que caracteriza a patologia, consiste em modalidades específicas de internalizar a figura do outro por parte do indivíduo. Dentro dessa perspectiva, fazer diagnóstico é identificar e explicitar o modo de existir do sujeito em seu relacionamento com o ambiente em determinado momento e os significados que ele constrói de si e do mundo.
\end{abstract}

Palavras-chave: fenomenologia, existencialismo, pscicopatologia, diagnóstico

\section{The psychopathology and the diagnosis according to the phenomenological-existentialist approach}

\begin{abstract}
Starting from the explanation of some premises of phenomenology and existentialism, some thoughts are given to the theoretical and methodological aspects concerning the psychopathology and the diagnosis according to this approach. A Psychology based on the phenomenological existentialist approach confirms the priority of the relationship with the other person on the subject's constitution. In this sense, the relational aspect takes a determining role on the healthy or pathological development. In addition, the essential aspect of the human existence from which the relational problems, the ones that characterizes the pathology, originate consists of specific ways of internalizing the other's image by the person. From this point of view, making a diagnosis consists of identifying and showing the person's way of being in his/her relationship with the environment at a specific moment and the meanings of himsel and the world.
\end{abstract}

Key-words: phenomenology, existentialism, psychopathology and diagnosis

\footnotetext{
${ }^{1}$ Gestalt Terapeuta; Mestre e Doutoranda em Psicologia Clínica pela Universidade de Brasília-UnB; exprofessora da Universidade de Fortaleza-UNIFOR; professora doCentroUniversitário de Brasília-UniCEUB; membro efetivo da diretoria e do corpo docente do Instituto de Gestalt Terapia de Brasília-IGTB.
} 


\section{A fenomenologia e o existencialismo: alguns pressupostos básicos}

O existencialismo é uma corrente filosófica bem mais abrangente e com uma gravitação no pensamento contemporâneo bem maior que a fenomenologia.

Nascido oficialmente em 1927, com a publicação de Ser e Tempo, de Martin Heidegger, o existencialismo coloca a questão do ser como a máxima tarefa da reflexão e da ação humana. Centrada sua preocupação na elucidação ontológica em geral, Heidegger focaliza sua atenção na questão do ser humano em particular, tentando caracterizar, em sua obra fundamental, os traços distintivos da existência humana. Para esse objetivo, ele entende que o único método que lhe permite alcançar este propósito é a fenomenologia.

Depois de Heidegger, outros pensadores identificados com essa corrente filosófica aplicam este mesmo método. No entanto, o método fenomenológico não é o único empregado pelo enfoque existencial, sobretudo na área da psicologia. Dois outros métodos gozam igualmente de considerável prestígio: o método compreensivo e o método dialético, que serão abordados posteriormente.

$\mathrm{Na}$ cabeça de seu fundador, Edmund Husserl, a Fenomenologia nasceu com a pretensão de tornar a reflexão filosófica uma ciência rigorosa tão bem estabelecida que servisse de fundamento a todas as outras ciências empírico-físicas e naturais. $\mathrm{O}$ grande intuito de Husserl era fundar um método que proporcionasse um conhecimento indubitável e radical, com um ponto de partida evidente, sem nenhum pressuposto. Trata-se de apreender os fenômenos tais como emergem na consciência pura do sujeito, na experiência vivida (Romero, 1997).

A aplicação do método fenomenológico, exige, em primeiro lugar, a vontade de ater-se aos fenômenos mesmos, deixando de lado qualquer pressuposto e toda idéia preconcebida.

Essa exigência metódica implica que precisamos deixar que os fenômenos falem por si mesmos sem encaixá-los de imediato na bitola de nossa teoria prévia (Romero, 1997, p. 53).

Embora não desconsidere o aspecto objetivo, a descrição fenomenológica se centraliza na experiência vivida pelo sujeito. Tenta captar o acontecer experiencial tal como o sujeito o manifesta por sua expressão verbal ou escrita, objetiva ou subjetiva. Pela fenomenologia tentamos indagar os modos de manifestar-se de um determinado fenômeno, examinando em seguida o significado e sentido que esse fenômeno possa comportar, tal como ele é apreendido pela análise reflexiva.

A fenomenologia, no entanto, não aspira apenas fazer uma descrição dos 
objetos intencionais que constituem a experiência originária da consciência; propõe-se também estabelecer a essência dos fenômenos. Nas múltiplas e variadas manifestações de um fenômeno, sempre podemos detectar um núcleo comum e um significado que percorrem e unificam essa variedade fenomenológica; é o que denominamos a essência do fenômeno (Romero, 1997).

Outro importante aspecto da fenomenologia é a noção de intencionalidade da consciência: a consciência é sempre consciência de alguma coisa, estando dirigida para um objeto, só existe objeto para uma consciência.

Se um objeto é sempre objeto-para-uma-consciência, ele jamais será objeto-em-si, mas objeto percebido... Consciência e objeto não são entidades separadas na natureza, mas definem-se a partir desta correlação que lhes é co-original (Boris, 1994, p. 23).

O campo da análise fenomenológica seria elucidar a essência desta correlação, na qual se estende o mundo inteiro (Angerami, 1984).

Neste sentido, como diz Romero, (1997), temos que considerar o caráter intencional do fenômeno psíquico. O mental não é algo que acontece apenas dentro da cabeça, sem maior relação com o mundo fora. Pelo contrário, o mental está inteiramente direcionado para o mundo; é o mundo refletido, de certa maneira, numa determinada pessoa. Uma vivência não é uma experiência puramente objetiva; toda vivência é uma forma de relação que o sujeito estabelece com os diversos objetos que constituem seu mundo. Buscar a compreensão do significado que esse mundo particular tem para cada sujeito, por meio da descrição minuciosa de suas vivências, é, portanto, o principal objetivo do método fenomenológico.

Finalmente, como diz Merleau-Ponty (1973), a mais importante aquisição da fenomenologia é, sem dúvida, a de ter associado o extremo subjetivismo ao extremo objetivismo, propondo caminhos para a compreensão da experiência humana visando respeitar a complexidade do real e encontrar o sentido dentro do próprio fenômeno, que emerge espontaneamente na consciência.

O existencialismo é uma filosofia da liberdade. Sustenta que o homem é ontologicamente livre. Por sermos livres, somos igualmente responsáveis. Sem liberdade de decisão e de escolha não seríamos responsáveis. Isso não significa negar a importância dos determinismos que, nas diversas esferas, afetam os homens. Justamente perante esses determinismos é que tem sentido a liberdade. Quando afirmamos que somos livres, estamos afirmando que sempre temos alguma possibilidade de escolha, uma margem de opção. Podemos submeter-nos passivamente a estes determinismos; é o que faz muita gente, mas essa sujeição 
é também uma forma de escolha (Romero, 1997).

De acordo com o existencialismo de Sartre, "a existência precede a essência", isto quer dizer, então, que a existência é a essência do homem. Sua essência só é revelada e, de certo modo, construída por meio de sua existência, de sua relação com o mundo (Penha, 1982).

É importante salientar, no entanto, que o existencialismo não nega as essências como determinações formais, estruturais ou naturais; elas constituem o dado ou recebido na constituição humana. Só que vale sempre a observação de Sartre: "Não importa o que me foi dado, o importante é o que eu faço com o que recebi".

O existencialismo também afirma que o homem é um ser de possibilidades. Em psicologia costuma-se acentuar a importância da necessidade como um fator que compele o indivíduo na procura do objeto que satisfaça uma carência biológica ou motive sua realização psíquica e existencial. Mas o homem não é meramente movido por carência e desejos; é um ser aberto ao mundo, aberto a seu apelo e às suas possibilidades. Por estar aberto, não está inteiramente determinado e já feito de uma vez - como acontece ao animal, que não tem futuro nem passado, sem possibilidades e completamente inserido na natureza.

Outra característica importante da existência humana é sua temporalidade e finitude.

O homem é um ser temporal e temporalizante, isto é, finito e ciente de sua finitude; tudo o que faz e lhe acontece revela sua finitude. O Dasein, ensina Heidegger, é um ser-para-a-morte. (Romero, 1997, p. 34)

Nas palavras de Augras (1986, p. 32):

O ser para a frente de si mesmo nada mais é do que o ser para a morte. É essa certeza inaceitável que fundamenta a ambigüidade do horizonte existencial. Todos os mitos de tempo são mitos de cataclismos, que buscam no fim do mundo uma promessa de ressurreição... o tempo é criação do homem, não apenas na forma de parâmetro que facilita a ordenação das ações humanas, mas sobretudo como tentativa de negar a morte.

O homem como ser no mundo é uma das dimensões existenciais apontadas por Heidegger. Com relação a este aspecto Heidegger explica que homem e mundo invocam-se mutuamente, um não existe sem o outro. Isso significa que o mundo é uma realidade puramente humana. O indivíduo está inserido completamente nessa realidade. Sair dessa realidade é perder as características próprias do ser 
humano. Tudo o que nos acontece subjetivamente se relaciona com algo que está ai, no mundo (Barbosa, 1998).

Diante de todas essas condições existenciais que lhe são inerentes, o ser humano inevitavelmente sofre e se angustia.

Segundo Petrelli (1999, p. 23),

A essência do homem é dada pelas tarefas do seu existir que são: ser consciente; escolher; decidir; ser responsável; aceitar sua finitude; aceitar os seus limites; responder às possibilidades; resistir às derrotas; construir a sua singularidade sobre a sua solidão; vencer o Nada constituindo-se como 'deus'.

Essas tarefas, cujas realizações e possibilidades de fracasso definem o sentido de sua própria existência, são a razão de sua profunda angustia. O homem consciente de sua própria humanidade se angustia diante de sua liberdade e responsabilidade; diante do nada (morte) e de sua inalienável singularidade e solidão, ao perceber que sua experiência de estar no mundo, além de finita, é vivida de um modo particularmente seu, nunca igual à experiência de qualquer outra pessoa.

\section{Os métodos compreensivo e dialético: uma breve exposição}

Enquanto modelo epistêmico ou forma de entender a existência humana em suas manifestações saudáveis ou patológicas, o enfoque fenomenológicoexistencial segue basicamente os métodos compreensivo, dialético e fenomenológico. (Romero, 1997).

A compreensão não é apenas a resultante do entendimento. Quando enxergamos as relações que constituem um determinado fenômeno ou uma dada situação, dizemos que os compreendemos. A compreensão é um método diferente do método explicativo, embora os dois se complementem. A psicologia usa um ou outro, segundo o plano em que se movimenta. Explicamos os processos psíquicos quando decorrem de fatores causais ou de variáveis independentes.

Explicamos alguns aspectos da conduta do bêbado sob o efeito do álcool (lentidão dos reflexos, falta de coordenação motora, incoerência associativa). Compreendemos a reação de esquiva e rejeição por parte da maioria das pessoas perante a presença de um bêbado, pois seu comportamento inconveniente torna indesejável sua proximidade. O explicar corresponde à determinação das causas; o compreender implica o conhecimento dos motivos que levam uma pessoa a comportar-se de uma determinada maneira, ou a vivenciar a realidade de certo 
modo. Compreender é relacionar um fenômeno psicológico com outro fenômeno psíquico com o qual mantém uma relação motivacional.

Certas condutas estranhas de uma pessoa idosa são explicáveis por deterioramento cerebral; perda de memória, emotividade pueril, diminuição de senso moral. Outras vivências são compreensíveis por motivos existenciais e psicológicos: suas fases de tristeza e certa melancolia relacionam-se com sua falta de possibilidades, seu isolamento de fato, a desconexão com certas atividades (aposentadoria) e o menosprezo notório de outros em relação ao velho.

Dessa maneira, compreender é estabelecer as relações de sentido que um evento, uma vivência, uma conduta ou uma expressão possam implicar.

O método dialético parte do princípio de que a relação com o diferente e o conflito entre os opostos são a força propulsora da evolução do ser humano. Esses opostos ou polaridades são as mais diversas possíveis, constitutivas da existência humana: consciência/inconsciência; figura/fundo; organismo/meio; eu/tu; sujeito/objeto; dentro/fora; vida/morte, etc. Existe uma tensão natural entre diversas polaridades vivenciadas pelo sujeito enquanto ser consciente e relacional. Este sujeito, na tentativa de integrar essas polaridades, sofre, entra em conflito e ansiedade, se desequilibra, se desorganiza, mas em seguida retoma um estado de equilibração, organização e harmonia provisório, no entanto, qualitativamente superior e mais complexo que o estado anterior.

O desenvolvimento humano, portanto, acontece como uma espiral, onde o conflito entre as diferenças é fundamental. É um constante processo de equilibração e desequilibração, organização e desorganização, mediante a dinâmica entre os opostos: tese e antítese, gerando uma nova totalidade provisória que é a síntese.

Como diz Augras (1986, p. 11)

A saúde encontra-se nesse fogo de interações. Pois cada estado de equilíbrio alcançado destrói o estado anterior. A vida procede dialeticamente. Ordem e desordem são etapas constantes no desenvolver do homem e do mundo.

Neste sentido, Augras define saúde e doença como etapas de um mesmo processo de equilibração na relação eu/mundo por meio do qual se dá a constituição mútua do mundo e de si mesmo.

\section{A psicopatologia: algumas idéias fundamentais}

A abordagem fenomenológica existencial da Psicopatologia, de acordo com Romero (1997), iniciou-se com a publicação do livro de Karl Jaspers, Psicopatologia 
Geral, em 1913. Nesse mesmo ano, o filósofo Edmundo Husserl publica seus escritos sobre Fenomenologia Pura, em que se estabelecem os traços gerais do método. Contudo, só em 1927, com a publicação de Ser e Tempo, de Martin Heidegger, é que se estabelece o consórcio da fenomenologia com o existencialismo.

$\mathrm{O}$ enfoque fenomenológico-existencial da psicopatologia tem como base uma concepção elaborada de homem, que se encontra desenvolvida nas grandes figuras deste movimento, singularmente em Heidegger, Sartre, Merleau - Ponty, Ortega e Buber.

De uma forma mais sucinta podemos definir o conceito de homem dentro deste enfoque como um ser pluridimensional, livre, inserido em um mundo dotado de sentido particular, aberto às suas possibilidades, consciente de sua finitude e de sua responsabilidade perante suas escolhas, capaz de inventar e cuidar de sua própria existência mediante a práxis.

Partindo desta visão de homem, podemos dizer que a psicopatologia vai se manifestar por meio de uma vivência de sofrimento onde a pessoa se sente vítima e presa a um destino sombrio e a uma existência destituída de realizações gratificantes e prazerosas. Sem liberdade de escolha, a pessoa vive a sensação de estar encurralada pelas circunstâncias da vida, sentindo-se impotente para modificálas, submetendo-se a elas, num sacrifício alienante e inevitável.

Nesse processo de sofrimento, a pessoa perde o contato com as possibilidades existentes no campo organismo/meio, percebendo a si mesma e ao outro de forma distorcida. Com relação a este aspecto, Romero (1977, p. 34) comenta:

Na depressão, o sentimento de falta de possibilidades é muito acentuado. Na ansiedade o que emerge são possibilidades negativas ou conflitantes. o possível e o impossivel perdem seus limites na psicose e quando ingressamos no plano do imaginário.

Uma psicologia de base existencial-fenomenológica é relacional e intersubjetiva isto é, confirma a prioridade da relação com o outro na constituição do sujeito. Isso significa que na etapa inicial do desenvolvimento, durante boa parte da infância, o indivíduo esteve subordinado às injunções, aos ditames, às manipulações e ao domínio dos agentes socializadores: pais, parentes, educadores e programadores coletivos (mídia, principalmente).

Entretanto, para que haja um desenvolvimento saudável e uma constituição da individualidade é preciso que aconteça uma progressiva superação dessa primazia do outro, tarefa esta que implica um longo processo de autoconsciência e questionamento de si mesmo e do mundo em que se encontra inserido (Romero, 1977). 
Desse modo, o aspecto relacional da existência humana assume um papel determinante na constituição de um desenvolvimento saudável ou patológico. O conflito existente na relação indivíduo/meio gera uma tensão básica que é fundamental no desenvolvimento humano, no entanto,

...haverá doença se esse conflito subsistir em termos de desordem, permanecendo o indivíduo num comportamento estereotipado, invariante, alheio às suas possibilidades e do ambiente, ou reagindo inadequadamente... a saúde do indivíduo será avaliada em sua habilidade para recuperar o equilíbrio e superar a crise na relação com o ambiente, utilizando então sua capacidade criadora para transformar esse meio inadequado em mundo satisfatório. (Augras, 1986, p. 12).

A psicopatologia também pode manifestar-se como uma desorganização da cronologia existencial. Para o melancólico, o tempo afigura-se parado, imóvel, sem nenhuma perspectiva. As idéias de ruína, de culpabilidade surgem como tentativas de justificar a modificação profunda da estrutura da vivência temporal. Neste sentido, a perturbação dentro do tempo do melancólico deixa de ser sintoma, para ser causa. (Augras, 1986).

Na psicose, a vivência do horizonte temporal desaparece. A esquizofrenia, em muitos aspectos, pode ser descrita como perturbação essencial do espaço tempo. Uma doente declara: "Nada mais acontece, tudo parou nem eu mais vivo. Sinto que o meu coração não bate. Ele parou como meus braços que são de vidro. Não sei se hoje é ontem" (Augras, 1986).

De acordo com Augras (1986) grande parte da psicopatologia deveria ser reconstituída a partir de um estudo a respeito da maneira como o indivíduo se situa em relação à vivência do tempo e do espaço. Longe de serem aspectos adjetivos na expressão de experiências específicas, tempo e espaço afirmam-se como dimensões significativas do ser.

O papel do outro na constituição do eu é abordado pela filosofia dialógica de Buber, em que ele defende que toda a existência do homem está fundamentada na relação com o outro, ou seja, no diálogo. O ser se determina quando em relação, não existe o eu em si, pois o eu é posterior à relação, é a partir dessa relação que o eu delimita sua própria existência (Buber, 1979).

De acordo com a filosofia dialógica, os bloqueios neuróticos e até a desestruturação psicótica surgem, pelo menos em parte, porque outras pessoas (figuras parentais, principalmente) não foram capazes de entender, considerar e valorizar a experiência da criança. Em conseqüência, ela não pode sentir-se con- 
firmada e, portanto, não é capaz de apreciar e valorizar sua própria experiência, tem de rejeitá-la, alienando uma parte de si mesma, que vai tornar-se inconsciente (Hycner, 1995).

Como a criança, por sua própria condição de imaturidade, dependência e impotência com relação ao mundo adulto, possui uma estrutura de ego frágil e vulnerável, é fundamental, para seu desenvolvimento saudável, que esse mundo seja experienciado como sendo suficientemente confiável e acolhedor, caso contrário, ela terá que lidar com uma realidade insuportável e inevitável. Na impossibilidade de superar esse conflito ela o introjeta, causando uma divisão interna do self.

Segundo Romero (1997), o aspecto essencial da existência humana, do qual se origina a problemática relacional que caracteriza a patologia, consiste em modalidades específicas de internalizar a figura do outro por parte do indivíduo.

O sujeito neurótico internalizou a figura do outro como uma presença dominante, perante a qual o próprio sujeito se posiciona como ente secundário. Isso significa que para o neurótico o outro tem demasiada presença. $O$ neurótico está tão habitado pelo outro que quase sempre precisa tomar providências, tendo que apelar para truques no sentido de conquistar um espaço suficiente para ele mesmo nesse mundo (Romero, 1997, p.165).

Ainda a respeito da neurose, Romero (1997) afirma que o movimento da vida humana é uma espiral em aberto e, na neurose, essa espiral tende a fecharse num círculo limitante, supostamente protetor, pouco permeável, escassamente mutável, sufocante.

Romero (1997) diz, também, que o que caracteriza o círculo da neurose, além dos comportamentos peculiares a cada tipo, são alguns traços visíveis e pertencentes a todos as variações típicas: o predomínio de sentimentos negativos referidos ao mundo e, com maior freqüência, ao próprio sujeito. Há uma profunda insatisfação de fundo que não é superada por eventuais compensações nem por sucessos materiais, eróticos e até afetivos.

Os sentimentos negativos, os conflitos, a baixa auto-estima e o estado de impotência e de insatisfação geram no neurótico uma vivência de angústia, que é definida por Romero (1997) como angústia sintomática, diferente da angústia existencial, que é inerente à condição humana.

A angústia sintomática é perturbadora, limitante e restritora da liberdade, levando o sujeito a utilizar mecanismos repetitivos, em um circuito fechado interminável. É resultante de conflitos e de um processo de alienação de si mesmo. 
A angústia existencial, por sua vez, estimula o questionamento da situação originante e motiva a procura de novos caminhos. Está associada à experiência de liberdade e responsabilidade. É originada por circunstâncias que põem em jogo os valores de sentido, ou que estão associados a decisões definitivas.

Na psicose há um processo de profunda alienação de si mesmo e do outro, por conta de uma total impossibilidade de se estabelecer um diálogo com o outro $(\mathrm{Eu}-\mathrm{Tu})$. O outro teve que ser alienado por se revelar excessivamente poderoso e nocivo à preservação do eu. Esse eu tornou-se desconhecido em virtude de tantas defesas e negações de si mesmo, na tentativa de minimizar a ameaça externa.

O outro está no mundo do psicótico como uma figura parcial, contraditória e ambivalente, é um habitante estranho e fugidio, assemelhando-se a um ser fantasmático e desencarnado. O psicótico constrói um mundo dividido e fragmentário, alienado de um contato vital com a realidade, por não ter obtido um reconhecimento mínimo dos outros. Sem reconhecimento por parte do outro, o sujeito não se reconhece a si mesmo.

Não conseguindo transitar pelas vias comunitárias que o sistema necessariamente impõe, o sujeito se perde nos labirintos de seus conflitos, refugiando-se periodicamente ou permanentemente nos recintos imaginários, geralmente sombrios e espectrais (Romero, 1997, p. 32).

No psicopata, o outro está quase ausente: é apenas um objeto a ser considerado em determinadas circunstâncias, seguindo as exigências e conveniências do próprio sujeito. Podemos dizer que o outro não habita o espaço interno do psicopata, ao contrário do neurótico que é habitado demais pelo outro (Romero, 1997).

O mundo do psicopata está, portanto, praticamente desabitado por outros seres humanos, sendo freqüentado, apenas, por objetos de significação temporária; por isso, o psicopata parece tão insensível, tão desconsiderado e tão egocêntrico.

O psicopata não se reconhece propriamente no outro, que é o que lhe permitiria sentir-se verdadeiramente humano. Desse modo, sua liberdade fica trincada, uma vez que o sentido pleno da liberdade está baseado na realização do humano, compartilhada no mundo dos homens.

\section{Opsicodiagnóstico: uma proposta metodológica}

De acordo com o pensamento de Kierkegaard (Penha, 1982), nenhum prin- 
cípio, sistema ou idéia geral pode dar conta de explicar ou descrever a realidade humana, a vivência particular de cada pessoa.

O pensamento abstrato só pode compreender o concreto abstratamente, enquanto o pensamento centrado no indivíduo busca compreender concretamente o abstrato, apreendê-lo em sua singularidade, captá-lo em sua manifestação subjetiva. A realidade é o que aparece à consciência. A subjetividade é a realidade. A própria realidade é aquela de que o indivíduo tem maior conhecimento. (Penha, 1982).

Estes pressupostos existencialistas tornam-se fundamentais na construção da postura do psicólogo e dos objetivos de um processo diagnóstico. Dentro dessa abordagem, o psicólogo não tenta explicar e enquadrar a pessoa examinada em categorizações e parâmetros arbitrariamente teorizados, pois ele acredita que a vivência dessa pessoa é sua própria explicação, sendo ela a melhor interprete de si mesma.

Como explica Angerami (1984), uma quantidade muito grande de fenômenos da existência, cada vez mais mostram-se inatingíveis e incompreensíveis diante das teorizações vigentes de compreensão do homem. As teorias, em sua desvairada tentativa de explicação do homem, negam o experenciar da própria existência.

A pessoa doente é antes de tudo uma pessoa que sofre, que precisa em primeiro lugar ser compreendida a partir de seus sentimentos, sensações, emoções, enfim, de tudo que por ela é vivenciado.

A pessoa, no processo diagnóstico, deve ser apreendida como sendo um fenômeno único e, como tal, respeitada em sua totalidade; não deve, portanto, ser avaliada segundo normas e padrões de comportamento preestabelecidos, numa total revelia a sua própria existência. Seu nível de crescimento ou de maturidade deve ser dimensionado por meio dos projetos de vida por ela própria idealizados e de acordo com seu próprio mundo e contexto existencial.

O existencialismo, em sua exuberância, mostra que a existência é um contínuo vir a ser, um sempre ainda não, com a possibilidade de um poder ser. Desse modo, é totalmente inaceitável a rotulação do ser humano, aprisionando-o dentro de determinadas categorias diagnósticas (Angerami, 1984).

A fenomenologia é uma filosofia da experiência, anterior às explicações meramente psicológicas, sociológicas, ou historicistas oferecidas pela ciência. 
Isto faz com que o psicólogo fenomenológico-existencial assuma uma postura de escuta do ser, desvelando-se ao mesmo tempo em que este também se desvela, recusando-se a instalar-se na verdade ou em seu sistema de verdades e certezas (Costa, 1995).

A fenomenologia aponta para uma perspectiva metodológica denominada epoché, palavra grega que significa suspensão, cessação ou seja, a colocação entre parênteses de todo interesse naturalmente orientado.

A redução fenomenológica ou epoché deve ser assumida pura e simplesmente como uma modificação do olhar, visando uma compreensão da experiência natural, isto é, daquilo que emerge espontaneamente no aqui e agora, dentro do contexto relacional psicólogo-cliente. Desse modo, o Psicólogo assume o ato criativo do descrever e compreender o fenômeno que vem a seu encontro, que se manifesta por si mesmo. É um olhar e uma escuta ingênua, destituída de um saber a priori ou de predeterminismos, propiciando a manifestação e a compreensão do ser do cliente em sua essência (Costa, 1995).

Nesta perspectiva, o psicólogo não pode apreender o mundo vivencial da pessoa a ser diagnosticada, enquanto não suspender ou colocar entre parênteses todos seus pressupostos, sua própria visão de mundo e conceitos, tanto quanto for humanamente exeqüível no momento (Hycner, 1995).

Segundo Augras (1986), fazer diagnóstico dentro desta perspectiva é identificar e explicitar o modo de existência do sujeito em seu relacionamento com o ambiente em determinado momento e que feixes de significados ele constrói de si e do mundo. A adequada descrição fenomenológica do mundo particular, singular e concreto do sujeito e de sua situação atual tem de apoiar-se numa aproximação que procure apreendê-la em sua totalidade.

Da mesma maneira que o indivíduo é a medida de sua própria normalidade, em cada situação, o significado será buscado dentro daquilo que for manifestado. A objetividade desta apreensão configurada em diagnóstico apoiar-se-á em critérios de coerência, deduzidos daquilo que se ofereceu da história do indivíduo e das vivências presentes. A subjetividade é inevitável e o método fenomenológico propõe que diante do reconhecimento da mesma, por parte do psicólogo, é possível limitá-la, transformando-a em ferramenta para a compreensão do outro (Costa, 1995, p.32).

Finalmente, como podemos então definir o psicodiagnóstico dentro do 
ponto de vista fenomenológico-existencial? De acordo com Petrelli (1999, p. 23), o psicodiagnóstico, dentro desta abordagem, "é uma investigação intuitiva compreensiva dos mistérios da história da vida de uma existência singular".

Esta investigação intuitiva compreensiva deve ser feita seguindo alguns passos:

I - Observar e escutar a pessoa por inteiro, fazendo a suspensão definitiva de todos os conhecimentos a priori, de todo preconceito e até de toda hipótese pré-formada, aceitando e respeitando a singularidade existente na pessoa a ser diagnosticada.

De acordo com Romero (1997), esta observação e esta escuta devem ser feitas com base nas oito dimensões existenciais fundamentais:

1 - Dimensão ontológica do homem como ser-no-mundo

2 - Dimensão social e interpessoal

3 - Dimensão da práxis

4 - $\quad$ Dimensão corporal

5 - Dimensão motivacional

6 - Dimensão afetiva

7 - Dimensão espaço-temporal

8 - Dimensão axiológica (valores inerentes à existência social e individual).

II - Descrever cada experiência significativa, tentando achar o sentido fundamental mediante um método compreensivo fenomenológico que não apela para um código que, supostamente, nos entregaria as chaves do enigma existencial, mas que se atém ao sentido possível que o discurso e a experiência vivida têm para a própria pessoa.

III - Buscar as relações de sentido entre as diversas experiências vividas pelo sujeito, bem como entre os aspectos universais da existência humana, que foram redescobertas na construção de uma história de vida particular, descendo à intimidade dessa história, descobrindo o protagonista nas singulares vicissitudes de sua existência, sempre única e incomparável.

IV - Fazer uma leitura diagnóstica descritiva com base na significação dada pelo próprio sujeito, associada aos princípios teóricos pertinentes à história particular do mesmo. 


\section{Referências bibliográficas}

ANGERAMI, V. A. Existencialismo e psicoterapia, São Paulo: Traço, 1984.

AUGRAS, M. O Ser da Compreensão: Fenomenologia da Situação de Psicodiagnóstico, Petropólis: Vozes, 1986.

BARBOSA, M.F. A Noção de Ser no Mundo em Heidegger e sua Aplicação na Psicopatologia, Psicologia-Ciência e Profissão, Brasília: Conselho Federal e Regionais de Psicologia, 18(3): 2-13, 1998.

BORIS, G.D.J.B. Noções Básicas de Fenomenologia. Insight Psicoterapia, São Paulo: Lemos Editorial e Gráficos Ltda, IV (46): 19-25, 1994.

BUBER, M. Do Diálogo e do Dialógico. São Paulo: Perspectiva, 1979.

COSTA, V.S.M. Existencialismo - Fenomenologia e a Gestalt Terapia, Revista do I Encontro Goiano da Abordagem Gestáltica, Goiânia, I(1): 26-32, 1985.

HOLANDA. A. F. Diálogo e Psicoterapia: Correlações entre Carl Rogers e Martin Buber, São Paulo: Lemos Editoral, 1998.

HYCNER, R. De Pessoa a Pessoa: Psicoterapia Dialógica, São Paulo: Summus, 1995.

MERLEAU-PONTY, M. Ciências do Homem e Fenomenologia, São Paulo: Saraiva, 1973.

JASPES, K. Psicopatologia Geral, São Paulo: Atheneu, 1973.

PENHA, J. O que é Existencialismo, São Paulo: Editora Brasiliense, 1982.

PETRELLI, R. Humanizando o Psicodiagnóstico, Revista do VEncontro Goiano da Abordagem Gestáltica, Goiânia, V(1): 23-25, 1999.

ROMERO, E. O Inquilino do Imaginário: Formas de Alienação e Psicopatologia, São Paulo: Lemos Editoral, 1997. 